\title{
Discurso, poder e processos de subjetivação: a infancia na sociedade de controle
}

\author{
Discourse, power and subjectivation processes: \\ childhood in control society
}

\author{
Antônio Fernandes Júnior
}

Universidade Federal de Goiás, campus Catalão, Catalão, GO, Brasil

\begin{abstract}
Resumo: Este trabalho propõe mobilizar conceitos da Análise do Discurso (AD) buscados em Michel Foucault como estratégia de leitura discursiva para o texto literário. A partir desse ponto de encontro, pretendemos abordar os discursos sobre infância, construídos nas letras das canções “Criança não trabalha" (1996) e "Pequeno cidadão" (2009), de Arnaldo Antunes. Para tanto, pretendemos articular o conceito de devir-criança (Deleuze) às reflexões de Michel Foucault sobre a governamentalidade e os processos de subjetivação, com o objetivo de apreender outros lugares e modos de conceber a infância na atualidade.
\end{abstract}

Palavras-chave: Discurso. Texto literário. Processos de subjetivação.

Abstract: This work aims to mobilize concepts of Discourse Analysis (DA) found in Michel Foucault as strategy of discursive reading to the literary text. Based on this encounter, we aim to approach the discourses on childhood, presented in the song lyrics "Criança não Trabalha" (1996) and "Pequeno Cidadão" (2009), by Arnaldo Antunes. Therefore, we aim to articulate the child-becoming concept (Deleuze) to reflections on Michel Foucault on governability and subjectivation processes with the purpose of apprehending other modes of conceiving childhood today.

Keywords: Discourse. Literary text. Subjectivation processes. 


\section{Considerações iniciais}

Este trabalho propõe mobilizar conceitos da Análise do Discurso buscados em Michel Foucault como estratégia de leitura para a construção da infância em poemas de Arnaldo Antunes. A obra desse poeta é, frequentemente, atravessada por uma aproximação com a infância, construindo uma "zona de vizinhança" com o universo infantil. Ao referirmo-nos à expressão "zona de vizinhança", dialogamos com Deleuze e Guattari e suas reflexões sobre a literatura e o devir-criança na literatura. Esse

Antônio

Fernandes

Júnior

158 conceito possibilita ler/ver a infância a partir de uma relação de alteridade que nos inquieta e desafia a construir outros lugares para a infância em nossa sociedade, cuja característica pauta-se em um deslocamento e em uma concepção de arte como micropolítica. Refletir sobre a infância, diante dessas questões, pressupõe abdicar de noções como faixa etária ou de noções "infantilizadas" sobre a criança, concebendo-a como um outro, com todas as possibilidades de linhas de fuga e capacidades expressivas.

Neste estudo, pretendemos articular o conceito de devir-criança às reflexões de Michel Foucault sobre a governamentalidade e os processos de subjetivação, com o intuito de pensarmos outras estratégias de invenção da infância. Essa discussão será acionada como ferramenta de leitura para as canções "Criança não trabalha" (1996) e "Pequeno cidadão" (2009), de Arnaldo Antunes, com o objetivo de apreender outros modos de conceber a infância na atualidade. Como vivemos em uma sociedade em que o discurso é controlado, selecionado e organizado, acreditamos que a infância também não foge à regra e, por isso, não escapa aos procedimentos e jogos de poder criados como tentativa de capturá-la. Assim, ao eleger a brincadeira como traço constitutivo da infância e da poesia, Antunes, nos poemas citados, concebe outros modos de subjetivação para a infância, discursivamente mobilizados e elencados como direitos do "pequeno cidadão".

\section{Arnaldo Antunes: traços de uma poética}

A escolha da obra de Arnaldo Antunes acompanha-nos a algum tempo e nos serve como ponto de referência para pensar o poético além dos limites impostos pelo formato convencional do poema em verso. A poética desse autor, como já tivemos oportunidade de explorar em outros trabalhos (FERNANDES JR., 2011), extrapola os limites do verso e do livro tradicional, alcançando outros espaços de produção, circulação 
e recepção da poesia no contexto atual. Seja na canção, no poema ou no vídeo, esse poeta pesquisa e explora o formato do poema de maneira singular, sem perder de vista a busca por outras formas de produzir leituras sobre a linguagem, os sujeitos e a história.

Antunes é considerado por estudiosos da canção no Brasil como um músico e poeta capaz de transitar, com muita habilidade, do poema para a letra da canção e da letra da canção para o poema. Os poemas desse autor, além de circularem em diferentes suportes, circulam por códigos também diferenciados, como a canção, o vídeo, o livro e o palco, para citar alguns exemplos.

São questões que merecem um exame atento e cuidadoso, visto que a canção e o poema são registros de natureza distinta, um para ser cantado e o outro para figurar como texto escrito. Independente do registro e do caráter híbrido dos códigos, o estudo da letra da canção, embora seja ainda visto pela academia com certas reservas, já conquistou espaço nos estudos literários, discursivos, entre outros, cujos enfoques abrangem vários compositores e estilos musicais.

Em muitos textos da obra desse artista, deparamo-nos com letras de músicas que, mesmo desvinculadas dos recursos melódicos da canção, podem ser lidas como um poema. Essa sustentabilidade das letras das canções de Antunes contribui para diminuir as diferenças peculiares aos dois códigos (letra de música e poema), pois se afasta de uma dada caracterização geral, atribuída às letras de músicas, como textos frágeis e sem o vigor de um poema escrito. De fato, mesmo na produção de Antunes, determinadas letras, se lidas sem os recursos melódicos que as integram, deixam o leitor com a sensação de que falta alguma coisa, pois, em geral, as letras de música são frágeis quando lidas, mas fortes quando cantadas, como bem pontuou Augusto de Campos, citado por Gardel (1998). Essa capacidade de transitar da canção ao poema é um traço peculiar às produções de Antunes, sobretudo pela capacidade de trabalhar com diferentes códigos. Isso não quer dizer que estamos diante de uma poética pioneira na literatura e na música produzida no Brasil ${ }^{1}$. Sendo assim, Arnaldo Antunes, herdeiro dessa tradição, da qual Vinicius de Moraes seria um bom exemplo, solidifica e/ou reverbera o vigor e a representatividade da canção no cenário artístico-cultural brasileiro.

1 Na produção musical brasileira, encontramos um conjunto de compositores, cujas letras de canções se sustentam como texto a ser lido, tal como o poema. Determinadas canções de Chico Buarque, Caetano Veloso, Gilberto Gil e outros encaixam-se nessa proposta. 
Dessa forma, como já tivemos oportunidade de observar em estudo já citado, esse movimento entre a canção e o poema, ou vice-versa, explicita um dado recorrente da poética de Antunes: uma canção pode migrar para o livro. Isso também não pode ser classificado em termos de regra fixa, visto que, frequentemente, os textos desse poeta transitam de um código e de um suporte para outros, recebendo ou não modificações.

Nessa acepção, cabe ressaltar as palavras de Gardel (1998), quando afirma que "é necessário não esquecer que a letra da canção é, antes

Antônio

Fernandes

Júnior

160 de tudo, palavra, em suporte expressivo distinto, em codificação contextual particular, mas palavra" (p. 113). Com essa citação, reiteramos a opção pela análise da letra da canção, como um recorte metodológico, considerando esse gesto como uma possibilidade de leitura que também pode contribuir para o estudo da obra do compositor aqui escolhido.

\section{Conexões entre poesia e infância}

A relação entre poesia e infância não se configura como uma particularidade ou novidade encontrada somente na obra de Antunes. São vários os momentos, seja na literatura, seja na canção, em que poetas e cancionistas articulam, cada qual ao seu modo, o poético com o universo infantil. Poetas como Mário Quintana e Manoel de Barros fazem constantes referências ao brincar da criança e ao criar do artista, discussão que remete às reflexões freudianas. No ensaio "Escritores críticos e devaneio" (1974), Freud explicita que, ao brincar, a criança fantasia um outro universo regido por outra lógica e sustentada pela invenção que ali se produz. Em termos associativos, o poeta, assim como a criança, fantasia um universo com vida própria, possibilitado pela linguagem.

Do ponto de vista do diálogo com a infância, tema deste estudo, a produção de Arnaldo Antunes conta, atualmente, com um conjunto de estudos significativos no meio acadêmico. Entre esses trabalhos publicados, encontramos, em diferentes momentos e abordagens, alusões e/ ou referências a uma dada forma de olhar o mundo do ponto de vista da criança. Acreditamos que Antunes não imita ou copia o pensamento infantil, mas estabelece um ponto de contato com a infância, uma "zona de vizinhança" entre os poemas e o universo infantil. Trata-se de outro movimento construído e "entranhado" na escritura dos poemas.

Ao referirmo-nos à expressão "zona de vizinhança", dialogamos com Deleuze e Guatari e as abordagens desses filósofos sobre o 
conceito de devir-criança e a literatura. Esse conceito possibilita-nos compreender um efeito discursivo materializado na obra do poeta em estudo, responsável pela construção de uma zona de vizinhança entre poesia e infância, entre o brincar da criança e o criar do artista. Pretendemos, com esse conceito, analisar poemas de Arnaldo Antunes, cujo foco parece não corresponder a uma infância em particular nem a um dado modelo de infância.

Para Deleuze e Guattari (1997, p. 19),

Discurso, poder e

Devir é um rizoma, não é uma árvore classificatória nem geprocessos de nealógica. Devir não é certamente imitar, nem identificar-se; nem regredir-progredir; nem corresponder, instaurar relações correspondentes; nem produzir, produzir uma filiação, produsubjetivação zir por filiação. Devir é um verbo tendo toda sua consistência; ele não se reduz, ele não nos conduz a 'parecer', nem 'ser', nem 'equivaler', nem 'produzir'.

Como o devir não apresenta traços de imitação nem incorporação, importa-nos ressaltar como se dá a aproximação entre os poemas de Antunes com o universo infantil.

o devir-criança da/na literatura direciona-se, conforme os autores citados, não para a infância do poeta e/ou do sujeito que escreveu, mas para uma infância do mundo. Não se refere, também, a uma dada concepção de infância abordada pela psicanálise, vista como origem de traumas psíquicos ou fontes de aproximações, identificações e projeções com imagens edipianas. Restaurar a "infância do mundo" é, para Deleuze, a grande tarefa da literatura. Não se busca uma infância determinada, com faixa etária ou idade pré-fixada, mas um devir-criança, um entre-lugar que não aponta para o adulto nem para a criança em particular. O devir está sempre "entre" ou "no meio" (DELEUZE, 1997). Escrever, na concepção desse filósofo, é um caso de devir, sempre da ordem do inacabado, pois não basta somente impor uma forma de expressão à matéria vivida.

Pensar a infância, diante do que foi exposto até o momento, pressupõe abdicar das noções de faixa etária ou das noções "infantilizadas" da criança, para concebê-la como um outro, com todas as possibilidades de linhas de fuga e capacidades expressivas. O devir-criança na linguagem poética pode ser compreendido como elo com o elemento 
lúdico, o desejo, o prazer e o espontaneísmo característico da arte como micropolítica (ROLNIK, 2000).

Esses apontamentos nos levam a pensar a infância para além dos limites de idade, etapa evolutiva da vida ou pela oposição entre adulto e criança. Trata-se, como defende Larrosa (2000), de pensar a infância como alteridade, como um outro que desafia o modelo cristalizado do universo adulto e como o que delimita a linha de declínio do poder:

Antônio

Fernandes

Júnior

162

E se a presença enigmática da infância é a presença de algo radical e irredutivelmente outro, ter-se-á de pensá-la na medida em que sempre nos escapa: na medida em que inquieta o que sabemos (e inquieta a soberba da nossa vontade de saber), na medida em que suspende o que podemos (e a arrogância da nossa vontade de poder) e na medida em que coloca em questão os lugares que construímos para ela (e a presunção da nossa vontade de abarcá-la). Aí está a vertigem: no como a alteridade da infância nos leva a uma região em que não comandam as medidas de nosso saber e do nosso poder. (LARROSA, 2000, p. 185).

Nessa leitura foucaultiana concebida por Larrosa, a infância passa a ser vista como algo que inquieta a "ordem discursiva" do adulto, desafiando-o a repensar outras possibilidades de construção/condução da infância na sociedade. Trata-se de avançar no sentido de concebê-la no que esta tem de desvio, de indefinido e de resistência.

Esses apontamentos sobre devir-criança e alteridade da infância, vinculados à concepção de arte como micropolítica, levam-nos às seguintes indagações: qual o lugar da infância na atualidade? Como vêm se construindo relações de encontro/embates entre adulto e criança na sociedade? E quais as possibilidades de se pensar outras infâncias na atualidade? Como proposta de ilustração e busca de respostas a essas perguntas, escolhemos duas letras de música de Arnaldo Antunes, destinadas ao público infantil, intituladas "Criança não trabalha" e "Pequeno cidadão".

Interessa-nos problematizar, nessas canções, a articulação adulto/criança construída como um discurso que atravessa a construção dos textos de Antunes, cujos efeitos de sentido podem capturar diferentes sujeitos (adulto e criança) em distintos processos de subjetivação. Por esse motivo, a escolha do conceito de devir-criança discutido 
anteriormente. Junto a esse conceito pretendemos, também, discutir as noções de poder, sujeito e processos de subjetivação para leitura e análise dos poemas citados. Antes dessa abordagem, faz-se necessária uma articulação entre Análise do Discurso e Literatura, a partir de Foucault, para em seguida procedermos à leitura anunciada.

\section{Conexões entre Análise do Discurso e Estudos Literários}

A aproximação entre o campo dos Estudos Literários e dos Estudos do Discurso, mais especificamente da Análise do Discurso (AD), requer, inicialmente, que se considere o caráter interdisciplinar vinculado a ambas as áreas de estudos da linguagem; tanto um quanto outro são, em sua constituição, atravessados por perspectivas teóricas oriundas de outros campos do saber. A articulação entre Linguística, História e

Discurso, podere processos de subjetivação Psicanálise formou, em um primeiro momento, o campo epistemológico da AD, no início dos anos 60 do século XX. Tal como a AD, os Estudos Literários também se constituíram por meio do diálogo com outras áreas do conhecimento. Podemos destacar, a título de exemplo, o vínculo com a Linguística no Estruturalismo, o estudo sobre as condições de produção, recepção e circulação do texto no meio social, mobilizados pela Estética da Recepção, entre outros. Essa articulação fica mais evidente a partir dos questionamentos pós-estruturalistas, quando os estudos literários também passaram a dialogar com a história e outros enfoques de abordagem do texto literário que afastaram o estudo da literatura de uma perspectiva imanentista, de viés estruturalista, conforme explicita Gama-Khalil (2009).

Isso posto, podemos afirmar que a $\mathrm{AD}$ e os Estudos Literários, ao se afastarem da "imanência" do texto, conseguiram alargar seu campo de leitura e abriram outros "gestos de interpretação" para o estudo da linguagem, em suas diferentes manifestações. Assim, a aproximação entre a $\mathrm{AD}$ e os Estudos Literários, atualmente, torna-se um caminho de interpretação, a nosso ver, extremamente fecundo. Para a AD, no sentido, de focalizar outros objetos, o literário; aos estudos literários, pela possibilidade de focalizar o texto como uma prática discursiva e lhe oferecer outras possibilidades interpretativas, por meio de uma abordagem que relacione o objeto literário com as condições de produção no qual se insere, focalizando os seus atravessamentos com a história, com os aspectos ideológicos a ele vinculados e com a rede enunciativa na qual se insere e com a qual dialoga. 
Nesse sentido, a AD e os Estudos Literários mobilizam conceitos e propostas de análise, cada qual a seu modo, oriundos de teses foucaultianas, sobretudo quando passam, por exemplo, a problematizar a articulação entre linguagem e história, texto e outros textos, o texto e suas condições de produção, e a literatura enquanto espaço de materialização de diferentes discursos. É nesse contexto que os estudos de Michel Foucault têm sido de enorme relevância para a leitura do texto literário enquanto prática discursiva, atravessada por um domínio de

Antônio

Fernandes

Júnior

164 memória e constituída por uma rede de regularidades e dispersões, tal como o autor ilustra em Arqueologia do saber.

Não é nosso propósito, neste estudo, aprofundar essa discussão. Nosso objetivo, no momento, é mobilizar alguns conceitos que serão acionados na e para a leitura de duas letras de música de Arnaldo Antunes, indicadas anteriormente. Entendemos que canção se constrói pela junção de melodia e letra, amalgamadas e fundidas em uma modalidade artística com características próprias. Ao separá-las para a composição deste estudo, temos clareza do recorte escolhido e das limitações da análise. Por outro lado, não temos a pretensão de uma leitura definitiva das canções, mas, pelo contrário, pretendemos, por meio do recorte proposto, trazer contribuições ao estudo da obra do compositor, ainda que restrito aos aspectos verbais das canções "Criança não trabalha" (1996) e "Pequeno cidadão" (2009).

Essas canções mobilizam reflexões sobre os lugares que criamos para a infância em nossa sociedade, sobretudo, quando o poeta joga com a valorização da brincadeira, em oposição ao trabalho infantil. A partir dessa oposição, pretendemos discutir as relações de poder e de subjetivação que atravessam os discursos sobre a infância nas canções citadas. Como o discurso, na acepção foucaultiana, não é visto como algo estanque, mas como uma prática, interessa-nos apreender os posicionamentos dos sujeitos nas canções destacadas, pois o discurso é um "campo de regularidade para diversas posições de subjetividade" (FOUCAULT, 1995, p. 61).

\section{Olhares sobre o sujeito e o poder em Foucault}

No célebre ensaio "O sujeito e o poder", Michel Foucault (1995) explicita que as reflexões sobre o sujeito foram o centro de suas preocupações nas pesquisas desenvolvidas. A problemática do sujeito, da subjetividade e dos processos de subjetivação configurara-se como tema 
recorrente nos trabalhos do filósofo em sua trajetória intelectual, perpassando as diferentes etapas de sua obra: a arqueologia, a genealogia e a ética/estética da existência. No ensaio citado, Foucault explicita que o principal objetivo de suas pesquisas não foi o discurso nem o poder, mas o sujeito, procurando desenvolver uma história dos diferentes modos de subjetivação do ser humano construídos na e pela história.

O sujeito é então a categoria por meio da qual o poder e demais conceitos da obra do filósofo se articulam. Para Foucault, o sujeito não é uma substância imutável, transcendental ou natural, mas uma forma que se constrói de acordo com as situações e papéis ocupados na sociedade. Por isso, reitera que sempre lhe interessou "a constituição histórica dessas diferentes formas de sujeito, em relação aos jogos de verdade" (FOUCAULT, 2004, p. 275).

Discurso, podere processos de subjetivação figuras de subjetividade acarreta, como consequência, negar o sujeito universal, para tentar compreender formas de ser e modos de vida plurais, quando não marginais. Trata-se de desnaturalizar o sujeito como algo dado para pensá-lo enquanto construção e/ou fabricação histórica, atravessado por discursos e práticas que o constituem.

Por esse motivo, Revel (2005, p. 85), ao retomar o conceito de sujeito/subjetividade em Foucault, reitera essa questão pontuando que, "se o sujeito se constitui, não é sobre o fundo de uma identidade psicológica, mas por meio de práticas que podem ser de poder ou de conhecimento, ou ainda por técnicas de si". Foi esse o encaminhamento de Foucault ao longo de suas pesquisas sobre a construção histórica das subjetividades. Foucault, citado por Revel (2005, p. 85), afirma que, "no curso de sua história, os homens jamais cessaram de se construir, isto é, de deslocar continuamente sua subjetividade, de se constituir numa série infinita e múltipla de subjetividades diferentes, que jamais terão fim e que não nos colocam jamais diante de alguma coisa que seria o homem".

Pensar esse movimento de construção do sujeito ao longo da história implica problematizar a produção histórica da subjetividade ou os processos de subjetivação que possibilitam a construção do sujeito no e pelo discurso. Como desdobramento dessa questão, podemos também refletir sobre a questão do corpo, uma vez que este é também afetado pela exterioridade, pelo social. Nesse raciocínio, Pelbart (2003, p. 45) pontua que "todo sujeito vivo é primeiramente um sujeito afetado, um corpo que sofre de suas afecções, de seus encontros, da alteridade que o 
atinge, da multidão de estímulos e excitações, que cabe a ele selecionar, evitar, escolher, acolher". Desses apontamentos, interessa-nos pensar, para este estudo, a relação do corpo afetado pelas forças do mundo e a ideia de encontro, de encontro entre corpos. Essa escolha vincula-se aos apontamentos sobre sujeito/subjetividade arrolados anteriormente, pois corpo e subjetividade são afetados e afrontam as forças do mundo (o fora) e, ao mesmo tempo, são atravessados pelo encontro com outros corpos (alteridade). Esse encontro pode ser entre sujeitos ou do sujeito

Antônio

Fernandes

Júnior

166 consigo mesmo, apontando para o movimento/enfrentamento de forças envolvidas na relação que o sujeito estabelece com o mundo, com os discursos e com a história.

Tais apontamentos sobre subjetividade e processos de subjetivação vinculam-se diretamente às relações de poder, pois é sobre estas que os sujeitos se constituem, são classificados, deixam-se conduzir, criam resistências ou linhas de fuga. Se considerarmos que o poder implica ação e a reação e se exerce de formas variadas e multifacetadas no meio social, temos que considerar a dualidade poder/resistência como elemento constitutivo desse campo de forças, ou seja, um pressupõe o outro. Assim, a noção de poder e, por conexão, a noção de governo implicam a noção de sujeito. Condução de condutas, ação e reação: condição para o exercício do poder entre sujeitos. Cabe ressaltar que estamos diante de uma relação de micropoderes, que, por sua vez, distancia-se de uma leitura macro ou de algo localizado de cima para baixo.

A noção de governo/governamento ou governamentalidade vincula-se a essas questões, como uma força que leva um sujeito a mudar de lugar, a mudar de conduta, seja em relação aos outros, seja em relação a si mesmo. Em suma, somos governados pelos outros e por nós mesmos e estamos totalmente inseridos em uma complexa rede de poderes da qual e pela qual nos constituímos enquanto sujeitos, ora submissos ora resistentes, mas sujeitos que se reconhecem neste ou naquele lugar.

Se entendermos que o corpo e o sujeito são construídos ao longo da história, resta-nos apreender, por meio das práticas discursivas e não discursivas, como se deu essa fabricação e quais traços ou vestígios possibilitam captar essas formas de sujeito materializadas em diferentes discursos. É pelo discurso que vamos chegar ao sujeito e aos processos de subjetivação, seja pelos enunciados produzidos, seja pelas materialidades (imagética, sonora, verbal etc.) acionadas. Em nosso caso específico, o sujeito e os processos se subjetivação serão discutidos 
a partir de um objeto estético, uma canção, cuja letra recai no devircriança e explicita essa correlação corpo e sujeito no enfrentamento com as forças do mundo.

Nessa acepção, subjetividade e processos de subjetivação vivem em constantes jogos de forças, intensificando a relação entre sujeito e mundo. Isso significa que somos afetados o tempo todo por forças de diferentes intensidades; estamos "sempre em relação, sempre agenciando, sempre desejando e, por isso, sempre produzindo. Daí a subjetividade produzir e ser produzida, não porque esteja condicionada a repor qualquer objeto ausente, mas porque ela é autoprodução sem finalidade alguma", conforme aponta Lopes (2007, p. 198).

\section{Leituras das canções "Criança não trabalha" e "Pequeno cidadão"}

Em uma das discussões contidas no livro A ordem do discurso, Foucault (2003, p. 8-9) anuncia que os discursos são "selecionados, organizados e redistribuídos por um certo número de procedimentos que têm por papel exorcizar-lhe os poderes e os perigos, refrear-lhe o acontecimento aleatório, disfarçar a sua pesada e temível materialidade".

Essa afirmação nos direciona aos exercícios de poder que são construídos socialmente e que regulam aquilo que se pode e se deve dizer em dado momento e lugar. Se essa é uma condição da vida em sociedade, acreditamos que a infância não foge à regra, pois, inserida na "sociedade de controle", está submetida aos mesmos procedimentos de "captura" e organização social. Nosso objetivo é o de focalizar esses elementos nas canções selecionadas para discussão.

\footnotetext{
Pequeno cidadão (2009)

Arnaldo Antunes / Antonio Pinto

Agora pode tomar banho

Agora pode sentar pra comer

Agora pode escovar os dentes

Agora pega o livro, pode ler

Agora tem que jogar videogame

Agora tem que assistir TV
}

\author{
Criança não trabalha (1998) \\ Arnaldo Antunes / Paulo Tatit \\ Lápis, caderno, chiclete, pião \\ Sol, bicicleta, skate, calção \\ Esconderijo, avião, correria, \\ Tambor, gritaria, jardim, confusão \\ Bola, pelúcia, merenda, crayon \\ Banho de rio, banho de mar,
}

Discurso, podere processos de subjetivação 
Agora tem que comer chocolate

Agora tem que gritar pra valer

Agora pode fazer a lição

Agora pode arrumar o quarto

Agora pega o que jogou no chão

Agora pode amarrar o sapato

Antônio

Fernandes

Júnior

168
Pula sela, bombom

Tanque de areia, gnomo, sereia, Pirata, baleia, manteiga no pão

Giz, merthiolate, band aid, sabão

Tênis, cadarço, almofada, colchão Quebra-cabeça, boneca, peteca,

Botão, pega-pega, papel papelão

Criança não trabalha

Criança dá trabalho

Criança não trabalha

1, 2 feijão com arroz

3, 4 feijão no prato

5, 6 tudo outra vez

(๔ Rosa Celeste Editora (Universal)

/ Palavra Cantada - 68497062,

"Canções Curiosas", vários,

Palavra Cantada, 1998)

Em que medida os conceitos de devir-criança, discurso, poder e subjetividade podem ser acionados para a leitura dessas canções? Qual a articulação possível? Em primeiro lugar, tais conceitos nos direcionam para o tema da infância e do devir-criança, principalmente, por problematizar e delimitar uma dada construção da infância, cuja característica vincula-se ao brincar, configurando-se como um lugar do encontro do sujeito (a criança) com outras possibilidades de afeto e invenção de si, além da construção de outros lugares para a infância. Em segundo lugar, essas canções estão imersas em relações de poder e gorvernamento da infância pautados por regras e agenciamentos que a delimitam em um dado espaço social.

Vejamos, primeiramente, a letra a letra da canção "Criança não trabalha". Essa composição justapõe uma série de expressões ou palavras que se inserem em um dado campo discursivo da brincadeira/ 
diversão (pega-pega, esconderijo, boneca, bola, skate etc.) e do saber (lápis, caderno, giz etc.), todos enumerados e inseridos em uma formação discursiva que nos direciona ao universo infantil. Circunda a enumeração descrita o refrão "criança não trabalha/criança dá trabalho", cuja ênfase parece contrapor outro discurso ao apresentado na enumeração anterior. Se antes estávamos diante de uma formação discursiva pautada na brincadeira e na educação, agora, com os versos do refrão, deparamo-nos com outro discurso construído no texto, colocando o trabalho como território também da infância. Se o discurso da canção é categórico quanto à negação do trabalho infantil, é porque esse ainda se dá a ver enquanto discurso e enquanto prática social. Nesse sentido, temos dois blocos temáticos e a afirmação das oposições "brincadeira/ trabalho" atravessados por domínios de poder que veem a criança governada por forças que a classificam como mão de obra ou como um "pequeno cidadão", cuja conduta deve ser regida pela educação e pela brincadeira.

O refrão da canção pode funcionar como processo de subjetivação capaz de levar a criança a se constituir como um sujeito que se reconhece nesse lugar ("criança não trabalha"), mas pode soar como palavra de ordem para o "adulto" que exercita esse poder sobre a criança, ou para aquele que defende o contrário. Essa canção, atravessada por um devir-criança, captura tanto a criança quanto o adulto, via processo de subjetivação, levando-os a se reconhecerem em distintos lugares, papéis sociais e a se constituírem como sujeitos inseridos em determinadas práticas discursivas construídas historicamente.

A segunda canção, "Pequeno cidadão", explicita, de forma mais direta, a condição da criança enquanto "pequeno cidadão" com direitos e deveres na sociedade, obviamente, governado por um sistema de imposições, ordens e condutas. Se considerarmos que se atribuiu, historicamente, à criança o status de inferioridade ou de ser ainda incapaz de falar (in-fans) $)^{2}$, podemos sinalizar que a proposta da canção já avança,

2 Essa discussão aparece em Castello e Mársico (2007, p. 53) na definição do verbete "infância". Para os autores, um indivíduo de pouca idade é denominado in-fans, que remete tanto ao sentido de "não fala" quanto de é "incapaz de falar". Logo, "infans (substantivado) e infantia são empregados no sentido de 'infante', 'criança' e 'infância', respectivamente [...] Na verdade, são encontrados usualmente usos de infans referindo-se a pessoas que se aproximam inclusive dos treze ou quinze anos". Então, podemos entender, junto aos autores, que "infans não remete especificamente à criança pequena que não adquiriu ainda a capacidade de falar, mas se refere aos que, por sua minoridade, não estão ainda habilitados para testemunhar nos tribunais: infans é assim o que não se pode valer de sua palavra para dar testemunho". 
e muito, em reconhecer a criança como "um pequeno cidadão" e não apenas como um ser imaturo.

No corpo dessa canção temos, tal como a letra de "Criança não trabalha", dois blocos temáticos, opondo o gesto da permissão, materializado na repetição do verso "agora pode", e o gesto da obrigação, expressa no verso "agora tem". Ao primeiro, vinculam-se questões relativas aos exercícios escolares, como higiene e cuidados domésticos, e com o corpo; ao segundo, estão relacionadas ações direcionadas à brin-

Antônio

Fernandes

Júnior

170 cadeira, à diversão e à subversão, por exemplo. Esse movimento nos leva a pensar nos exercícios de poder vinculados à disciplina, que delimita horário para brincar, cuidar do corpo, ou seja, há horário para tudo e é preciso se inserir nessa lógica social. Se retomarmos Foucault, em A ordem do discurso, anteriormente citado, vimos que o discurso é selecionado, organizado e que há regras de controle e organização das atividades, inclusive para as crianças.

Tal como na primeira canção, a letra de "Pequeno cidadão" possibilita dois processos de subjetivação que capturam tanto a criança quanto o adulto que se reconhecem em distintos lugares e, de um modo ou de outro, estão imersos nas tramas do poder. Há, também, um devircriança funcionando como estratégia discursiva capaz de unir a criança e o adulto na composição do texto e do discurso.

Ambas as canções inserem-se em uma rede enunciativa, na qual diferentes posições de sujeito são acionadas e aparecem no discurso que nelas se materializa. Nessa memória discursiva comparecem os discursos contra a exploração do trabalho infantil e o diálogo com o Estatuto dos Direitos da Criança e do Adolescente, criado em 1990. Como se nota, essa normatização que visa à preservação dos direitos da criança é relativamente recente.

As canções discutidas inserem-se, também, em outra rede enunciativa, ligada a outros segmentos musicais, tais como o grupo Rumo, Palavra Cantada e outros que se propõem a produzir uma obra estética distante de produtos de massa de cunho moralista, piegas, que não valorizam a criança enquanto sujeito crítico na sociedade. São canções respaldadas por projetos poético-musicais criativos, capazes de nos colocar diante desse outro, a infância, e nos posicionar diante de nós mesmos, como seres atravessados por saberes e poderes que nos constituem. 


\section{Para finalizar...}

O que essas canções nos trazem como proposta para a infância? Como pensar os lugares que estabelecemos para as crianças ou como pensar outros lugares para elas? Se pensarmos o contexto no qual essas composições foram produzidas, podemos afirmar que ambas se propõem a pensar que outros lugares há para a criança na atualidade e que tipos de sujeitos elas colocam em jogo. Por isso, a afirmação da brincadeira e da educação constitui, em si, uma grande vantagem no processo de micropolíticas, cujo exercício de poder possibilita o estabelecimento e o reconhecimento dos direitos do "pequeno cidadão". Em segundo lugar, não estamos pensando as relações de poder como algo negativo ou simplesmente punitivo, mas como algo que possibilita a condução de condutas e que é capaz de promover o aprendizado das "regras" e, com

Discurso, poder e processos de subjetivação isso, mobilizar linhas de fugas, resistências.

Ao destacar o brincar como ponto central das canções, Antunes constrói outros modos de dizer e ver a infância não como algo fora do campo social, em um espaço onde não há relações de poder, pois é no meio social que as crianças se inserem e se constituem como sujeitos. Por isso, as duas canções podem capturar tanto o adulto quanto a criança e falar para ambos ao mesmo tempo, considerando que o devir-criança, tal como foi explicitado, funciona como uma estratégia discursiva capaz de produzir novas formas de invenção da infância, pautada no aprendizado das regras e na possibilidade de viabilizar a criação de novas formas de liberdade.

\section{Referências}

ANTUNES, Arnaldo. Pequeno cidadão. São Paulo: Microservice S\&D, 2009.

Criança não trabalha. Disponível em: <http://www.arnaldoantunes.com.br/new/sec_discografia_todas.php?filtro=c>. Acesso em: 10 mar. 2012.

CASTELLO, Luis A.; MÁRSICO, Claudia T. Oculto nas palavras: dicionário etimológico para ensinar e aprender. Belo Horizonte: Autêntica, 2007. 
DELEUZE, Gilles. Crítica e clínica. Trad. de Peter Pál Pelbart. São Paulo: Editora 34, 1997.

; GUATTARI, Felix. Mil Platôs: capitalismo e esquizofrenia. Trad. de Suely Rolnik. São Paulo: Editora 34, 1997. v. 4.

FERNANDES JR., Antônio. Os entre-lugares do sujeito e da escritura em Arnaldo Antunes. Curitiba: Appris, 2011.

Antônio

Fernandes

Júnior

FOUCAULT, Michel. Arqueologia do saber. 4. ed. Rio de Janeiro: Forense Universitária, 1995.

A ordem do discurso. 9. ed. São Paulo: Edições Loyola, 2002.

A ética do cuidado de si como prática de liberdade. In: MotTA, M. B. (Org.). FOUCAULT, Michel. Ética, sexualidade e política. Rio de Janeiro: Forense Universitária, 2004. p. 264-287. (Ditos \& Escritos, V).

Dois ensaios sobre o sujeito e o poder. In: DREYFUS, H.; RABINOW, Paul. Michel Foucault: uma trajetória filosófica. Rio de Janeiro: Forense Universitária, 1995. p. 231-249.

FREUD, Sigmund. Escritores críticos e devaneio (1908). In:

Obras completas. Rio de Janeiro: Imago, 1974. v. 9, p. 135-143.

GAMA-KHALIL, M. M. Veredas possíveis dos estudos discursivos sobre a literatura: as vozes de Michel Foucault e Mikhail Bakhtin nos campos da $\mathrm{AD}$ e da Teoria Literária. In: FERNANDES, C. A.; GAMA-KHALIL, M. M.; ALVES JR., J. A. (Org.). Análise do Discurso na literatura: rios turvos de margens indefinidas. São Carlos: Claraluz, 2009. p. 272-297.

GARDEL, André. Música popular e poesia brasileira contemporânea: aproximações e fugas. RANGE REDE, Revista de Literatura, Rio de Janeiro, ano 4, n. 4, p. 111-124, 1998. 
LARROSA, Jorge. O enigma da infância. In: Pedagogia profana: dança, piruetas e mascaradas. 4. ed. Trad. de Alfredo VeigaNeto. Belo Horizonte: Autêntica, 2000. p. 183-199.

LOPES, Marcius A. Loiola. Da Genealogia da moral a $\mathrm{O}$ anti-édipo: a imagem da 'falta' como ideal ascético. In: LINS, Daniel. Nietzsche/ Deleuze: imagem, literatura e educação. Rio de Janeiro: Forense Universitária; Fortaleza: Fundação de Cultura, Esporte e Turismo, 2007. p. 193-210.

Discurso, poder e processos de

PELBART, Peter Pál. O corpo do informe. In: Vida capital: ensaios de biopolítica. São Paulo: Iluminuras, 2003. p. 42-51. subjetivação

REVEL, Judith. Foucault: conceitos básicos. Trad. de Carlos Piovezani e Niltom Milanez. São Carlos: Claraluz, 2005.

ROLNIK, Suely. Os mapas movediços de Öyvind Fahstön. 2000. Disponível em: <http://www.pucsp.br/nucleodesubjetividade/ Textos/SUELY/Fahlstrom.pdf>. Acesso em: 15 jan. 2007. 